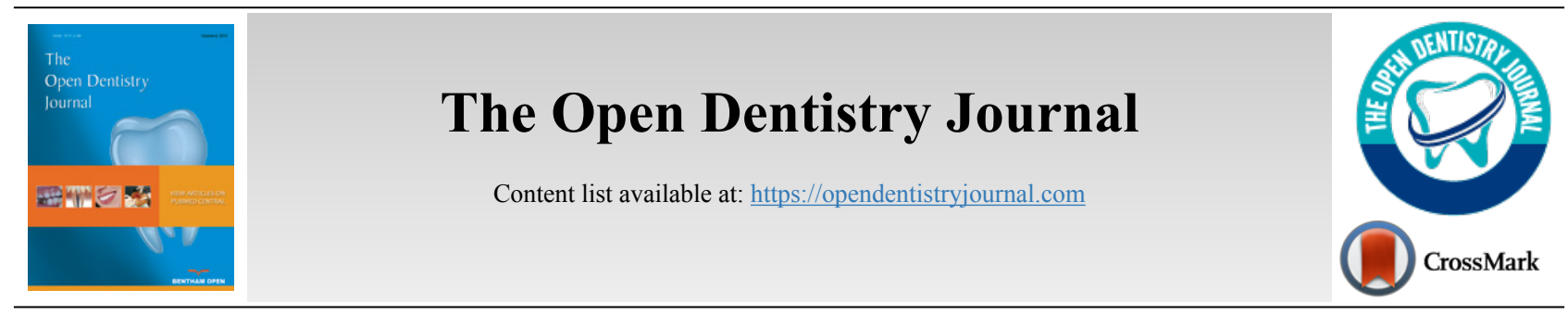

RESEARCH ARTICLE

\title{
Evaluation of the Knowledge and Awareness of Dental Patients in Saudi Arabia on Periodontal Health and Diseases
}

\author{
Eman Allam ${ }^{1,2}$, Nouf Alshibani ${ }^{3, *}$, Yara Alshibani ${ }^{3}$ and Reem Alkattan ${ }^{3}$ \\ ${ }^{I}$ Department of Preventive Dentistry, College of Dentistry, Gulf Medical University, Ajman, UAE \\ ${ }^{2}$ Oral and Dental Research Division, National Research Centre, Cairo, Egypt \\ ${ }^{3}$ Department of Periodontics and Community Dentistry, College of Dentistry, King Saud University, Riyadh, Saudi Arabia.
}

\begin{abstract}
:
Objective:

The aim of this study was to assess the periodontal health knowledge and awareness among a cohort of dental patients in Saudi Arabia.

Methods:

One thousand adult patients attending King Khaled University Hospital and the Dental Hospital, King Saud University, in Riyadh, KSA, were recruited to the study. The subjects completed a questionnaire that aimed to evaluate their level of awareness on etiology, risk factors, and preventive measures related to periodontal disease.

Results:

The study sample showed adequate awareness and general knowledge on signs and symptoms of periodontal diseases as well as risk factors for their development. Data also suggested great knowledge of oral hygiene measures for maintaining good oral hygiene. However, a low level of awareness was reported for the exact etiology of periodontal disease, as indicated by the fact that about $65 \%$ of respondents did not know or declined the fact that plaque causes periodontal disease. The participants also demonstrated a low level of awareness of the association between periodontal diseases and systemic conditions, such as coronary heart diseases and premature birth.

Conclusion:

The results of this study showed extensive variations and knowledge gaps between different aspects related to periodontal disease. In order for comprehensive oral health educational programs to be effective and to achieve their goals, they should be designed to fulfill these knowledge gaps and tailored to target the areas of least awareness, such as etiology and systemic conditions association.
\end{abstract}

Keywords: Knowledge and awareness, Periodontal diseases, Risk factors, Preventive measures, Systemic conditions, Oral hygiene.

\begin{tabular}{|l|l|l|l|}
\hline Article History & Received: May 22, 2020 & Revised: July 24, 2020 & Accepted: July 26, 2020 \\
\hline
\end{tabular}

\section{INTRODUCTION}

Periodontal diseases include all pathological conditions of the periodontium, but commonly refers to inflammatory conditions that are induced by dental plaque namely, gingivitis and periodontitis. The prevalence of periodontal diseases generally increases with age and is directly related to poor oral hygiene and plaque accumulation. While periodontal diseases, in general, are considered a major public health concern owing to their high prevalence and their effects on the individual's

\footnotetext{
* Address correspondence to this author at Department of Periodontics and Community Dentistry, College of Dentistry, King Saud University, Riyadh, Saudi Arabia; Tel: +966505459855;

E-mail: nalshibani@ksu.edu.sa
}

quality of life, severe periodontitis affects only $10-15 \%$ of the population in UK, and a much smaller proportion of the population (about 1 in 1000) is affected by aggressive periodontitis which results in severe loss of alveolar bone and deep periodontal pockets at a younger age. According to the data from the Health and Social Care Information Centre 2017, only $17 \%$ of adults were deemed to be periodontally healthy; that is, no pockets $>4 \mathrm{~mm}$ and no bleeding or calculus. $75 \%$ of the population had a periodontal pocket or attachment loss of at least $4 \mathrm{~mm}$ at one or more sites [1 - 5].

There have only been a few studies that attempted to estimate the prevalence of periodontal disease in the Saudi Arabian population. Guile et al. [6] used cluster sampling to 
evaluate periodontal status in adults in Central Saudi Arabia and found that around $50 \%$ of the studied households presented with active periodontal disease. Their results indicated that, in subjects aged 20-64 yr, 21-32\% had periodontal pockets of 4-6 mm while less than $8 \%$ of subjects younger than $35 \mathrm{yr}$ old had pockets of $6 \mathrm{~mm}$ or greater. Those aged between $35-44$ years had the most severe periodontitis, with over $18 \%$ having pockets of $6 \mathrm{~mm}$ or greater.

Oral hygiene behavior and seeking regular dental care are substantial determining factors for the prognosis of periodontal diseases. Oral health promotion and education should ideally be tailored to the level of knowledge, awareness, as well as the educational and socioeconomic level of the recipients. Patients tend to better comply with instructions when they are well informed and clearly supported. Inadequate knowledge and lack of awareness are among the reasons for non-compliance to oral hygiene directives [7 - 10]. Maintaining a healthy and positive oral hygiene behavior requires joint efforts from the dental professionals as well as the patients themselves and the community. The aim of the current study was to assess periodontal disease awareness among a cohort of dental patients in Saudi Arabia.

\section{MATERIALS AND METHODS}

The present cross-sectional study was carried out in the outpatient department of King Khaled University Hospital and the Dental Hospital, King Saud University in Riyadh, KSA. A convenience sample of 1000 patients was asked to participate in the study. A self-administered structured questionnaire was distributed to the patients to evaluate the level of awareness towards periodontal diseases. The questionnaire was designed by the authors and included questions about the personal and demographic data as well as questions about the knowledge, behavior, and practice awareness of oral hygiene procedures. The study was reviewed and approved by the Research Ethics Review Committee (Research project no E-17-2744). The questionnaire was pre-tested on a representative sample of 35 subjects to check for appropriateness and any required modifications. The first six questions determined the subjects' demographic profile and included information on gender, nationality, age, marital status, and education. The rest of the questions focused on assessing the level of awareness on periodontal diseases, in general, including etiology, associated risk factors, prevalence, symptoms, and complications.
All data were statistically analyzed using SPSS (Statistical Package for Social Science, IBM SPSS 21.0; Chicago, IL, USA). The data were subjected to descriptive analysis and was statistically represented in terms of numbers and percentages. A comparison between groups was made using the Chi-square test. Differences were considered statistically significant when the $\mathrm{p}$-values were $\leq 0.05$.

\section{RESULTS}

The total number of adult subjects participating in the survey was 1000 (414 males, 586 females, age range 18-65 years). More than three-quarters of the responders (about 79\%) were college-educated or higher, and more than half of them (58\%) reported belonging to a private educational institute. The sample moatly composed of Saudi citizens (92\%). The demographic characteristics of the participants are shown in Table 1.

Approximately $57 \%$ of the respondents were not aware that periodontal disease is caused by plaque and $55 \%$ thought that calculus is unpreventable. More than half of the respondents recognized that periodontal disease could lead to tooth loss, can cause frequent pain, and can remain unrecognized for years. While $90 \%$ of respondents stated that bleeding gums are a sign of periodontal disease, only $34 \%, 47 \%, 57 \%, 34 \%$ stated that bone loss, mobile teeth, gingival recession, tooth migration are signs of periodontal disease, respectively (Table 2 ).

Approximately $88 \%$ of the respondents believed that periodontal disease is not an older people disease, and more than half of the sample did not know that it would possess a risk factor for pre-term birth or coronary heart disease. About $90 \%, 55 \%$, and $29 \%$ recognized that smoking, diabetes, and stress are risk factors for developing periodontal diseases, respectively (Table $\mathbf{3}$ ).

$89 \%$ of the study sample were aware that managing to sustain a good oral hygiene can prevent periodontal disease and $71 \%$ reported that regular visits to the dentist would help. $65 \%$ reported that cleaning the occlusal surface is essential for avoiding periodontitis and $86 \%$ reported that brushing does not need to be firm. In general, more than $74 \%$ of the study sample believed that using toothbrush, toothpaste, floss, and mouthwash are necessary to maintain good oral hygiene (Table 4).

Table 1. Demographic characteristics of the study sample.

\begin{tabular}{|c|c|c|c|c|c|}
\hline Parameter & & No. & Percent & Chi-Square & P-value \\
\hline \multirow{2}{*}{ Gender } & Male & 414 & $41.40 \%$ & 29.584 & 0.001 \\
\cline { 2 - 6 } & Female & 586 & $58.60 \%$ & & \\
\hline \multirow{3}{*}{ Nationality } & Saudi & 919 & $91.90 \%$ & 702.244 & 0.001 \\
\cline { 2 - 6 } & Non-Saudi & 81 & $8.10 \%$ & & \\
\hline \multirow{3}{*}{ Age } & $18-25 \mathrm{yrs}$ & 293 & $29.40 \%$ & 549.124 & 0.001 \\
\cline { 2 - 6 } & $26-35 \mathrm{yrs}$ & 424 & $42.50 \%$ & & \\
\cline { 2 - 6 } & $36-45 \mathrm{yrs}$ & 70 & $19.50 \%$ & & \\
\cline { 2 - 6 } & $46-55 \mathrm{yrs}$ & 16 & $7.00 \%$ & & \\
\cline { 2 - 6 } & $56-65 \mathrm{yrs}$ & $1.60 \%$ & & \\
\end{tabular}


(Table 1) contd.....

\begin{tabular}{|c|c|c|c|c|c|}
\hline Parameter & & No. & Percent & Chi-Square & P-value \\
\hline \multirow{4}{*}{ Social Status } & Single & 362 & $36.40 \%$ & 1032.093 & 0.001 \\
\hline & Married & 610 & $61.40 \%$ & & \\
\hline & Divorced & 18 & $1.80 \%$ & & \\
\hline & Widow & 4 & $0.40 \%$ & & \\
\hline \multirow{5}{*}{ Educational Level } & Uneducated & 3 & $0.30 \%$ & 1325.161 & 0.001 \\
\hline & Less than high school & 47 & $4.70 \%$ & & \\
\hline & High school & 161 & $16.10 \%$ & & \\
\hline & College & 644 & $64.60 \%$ & & \\
\hline & Post-graduate studies & 142 & $14.20 \%$ & & \\
\hline \multirow{2}{*}{ Governmental/Private } & 1 & 417 & $41.70 \%$ & 27.556 & 0.001 \\
\hline & 2 & 583 & $58.30 \%$ & & \\
\hline
\end{tabular}

Table 2. General knowledge and awareness of periodontal diseases among the study sample (n=1000).

\begin{tabular}{|c|c|c|c|c|c|}
\hline Question & & No. & Percent & Chi-Square & P-value \\
\hline \multirow{3}{*}{ Periodontal disease is caused by plaque } & Yes & 351 & $35.20 \%$ & 357.982 & 0.001 \\
\hline & No & 80 & $8.00 \%$ & & \\
\hline & I don't know & 567 & $56.80 \%$ & & \\
\hline \multicolumn{6}{|c|}{ Which of these conditions are signs of periodontal disease } \\
\hline \multirow{3}{*}{ Bleeding Gums } & Yes & 892 & $89.50 \%$ & 1416.544 & 0.001 \\
\hline & No & 31 & $3.10 \%$ & & \\
\hline & I don't know & 74 & $7.40 \%$ & & \\
\hline \multirow{3}{*}{ Bone Loss } & Yes & 341 & $34.10 \%$ & 188.450 & 0.001 \\
\hline & No & 152 & $15.20 \%$ & & \\
\hline & I don't know & 506 & $50.70 \%$ & & \\
\hline \multirow{3}{*}{ Mobile Teeth } & Yes & 473 & $47.30 \%$ & 136.922 & 0.001 \\
\hline & No & 173 & $17.30 \%$ & & \\
\hline & I don't know & 354 & $35.40 \%$ & & \\
\hline \multirow{3}{*}{ Gingival Recession } & Yes & 566 & $56.70 \%$ & 351.586 & 0.001 \\
\hline & No & 83 & $8.30 \%$ & & \\
\hline & I don't know & 350 & $35.00 \%$ & & \\
\hline \multirow{3}{*}{ Tooth Migration } & Yes & 341 & $34.20 \%$ & 95.004 & 0.001 \\
\hline & No & 203 & $20.30 \%$ & & \\
\hline & I don't know & 454 & $45.50 \%$ & & \\
\hline \multirow{3}{*}{ Periodontal disease can lead to tooth loss } & Yes & 752 & $75.40 \%$ & 805.795 & 0.001 \\
\hline & No & 80 & $8.00 \%$ & & \\
\hline & I don't know & 165 & $16.50 \%$ & & \\
\hline \multirow{3}{*}{ One recognizes periodontal disease by frequent tooth aches } & Yes & 564 & $56.50 \%$ & 269.375 & 0.001 \\
\hline & No & 148 & $14.80 \%$ & & \\
\hline & I don't know & 287 & $28.70 \%$ & & \\
\hline \multirow{3}{*}{ One cannot avoid emergence of dental calculus } & Yes & 266 & $26.60 \%$ & 209.447 & 0.001 \\
\hline & No & 544 & $54.50 \%$ & & \\
\hline & I don't know & 189 & $18.90 \%$ & & \\
\hline \multirow{3}{*}{ Periodontitis often remains unrecognized for years } & Yes & 561 & $59.40 \%$ & 324.536 & 0.001 \\
\hline & No & 117 & $12.40 \%$ & & \\
\hline & I don't know & 266 & $28.20 \%$ & & \\
\hline
\end{tabular}

Table 3. Knowledge and awareness of risk factors associated with or related to periodontal diseases among the study sample $(\mathrm{n}=\mathbf{1 0 0 0})$.

Older people are only susceptible to periodontal disease

\begin{tabular}{|c|c|c|c|c|}
\hline Yes & $\mathbf{4 3}$ & $\mathbf{4 . 3 0} \%$ & $\mathbf{1 3 5 7 . 1 6 8}$ & $\mathbf{0 . 0 0 1}$ \\
\hline No & 881 & $88.30 \%$ & & \\
\hline I don't know & 74 & $7.40 \%$ & & \\
\hline
\end{tabular}




\begin{tabular}{|c|c|c|c|c|c|}
\hline \multicolumn{6}{|c|}{ Periodontal disease is a risk factor for } \\
\hline \multirow{3}{*}{ Pre-term Birth } & Yes & 67 & $6.70 \%$ & 600.434 & 0.001 \\
\hline & No & 250 & $25.00 \%$ & & \\
\hline & I don't know & 683 & $68.30 \%$ & & \\
\hline \multirow{3}{*}{ Coronary heart Disease } & Yes & 265 & $26.50 \%$ & 265.898 & 0.001 \\
\hline & No & 165 & $16.50 \%$ & & \\
\hline & I don't know & 569 & $57.00 \%$ & & \\
\hline \multicolumn{6}{|c|}{ Which of these are risk factors for periodontal disease } \\
\hline \multirow{3}{*}{ Smoking } & Yes & 892 & $89.50 \%$ & 1426.774 & 0.001 \\
\hline & No & 6 & $0.60 \%$ & & \\
\hline & I don't know & 99 & $9.90 \%$ & & \\
\hline \multirow{3}{*}{ Diabetes } & Yes & 545 & $54.60 \%$ & 299.321 & 0.001 \\
\hline & No & 100 & $10.00 \%$ & & \\
\hline & I don't know & 354 & $35.40 \%$ & & \\
\hline \multirow{3}{*}{ Pshycho Stress } & Yes & 289 & $28.90 \%$ & 210.878 & 0.001 \\
\hline & No & 172 & $17.20 \%$ & & \\
\hline & I don't know & 539 & $53.90 \%$ & & \\
\hline
\end{tabular}

Table 4. Knowledge and awareness of practice related factors to periodontal diseases among the study sample (n=1000).

\begin{tabular}{|c|c|c|c|c|c|}
\hline \multirow{3}{*}{ If one manages to sustain good oral hygiene, he will not suffer from periodontitis } & Yes & 889 & $89.10 \%$ & 1395.573 & 0.001 \\
\hline & No & 55 & $5.50 \%$ & & \\
\hline & I don't know & 54 & $5.40 \%$ & & \\
\hline \multirow{3}{*}{ To get the teeth clean by daily brushing one must brush them firmly } & Yes & 93 & $9.30 \%$ & 1264.150 & 0.001 \\
\hline & No & 862 & $86.30 \%$ & & \\
\hline & I don't know & 44 & $4.40 \%$ & & \\
\hline \multirow{3}{*}{ Patients can manage to sustain optimal oral hygiene without visiting the dentist } & Yes & 710 & $71.00 \%$ & 687.050 & 0.001 \\
\hline & No & 235 & $23.50 \%$ & & \\
\hline & I don't know & 55 & $5.50 \%$ & & \\
\hline \multirow{3}{*}{ To avoid periodontitis, it is important to brush the chewing surfaces } & Yes & 651 & $65.10 \%$ & 474.638 & 0.001 \\
\hline & No & 116 & $11.60 \%$ & & \\
\hline & I don't know & 233 & $23.30 \%$ & & \\
\hline \multicolumn{6}{|c|}{ Which one of the following is necessary to maintain good oral health } \\
\hline \multirow{2}{*}{ Toothbrush } & Yes & 877 & $92.90 \%$ & 695.021 & 0.001 \\
\hline & No & 67 & $7.10 \%$ & & \\
\hline \multirow{2}{*}{ Toothpaste } & Yes & 821 & $86.90 \%$ & 514.084 & 0.001 \\
\hline & No & 124 & $13.10 \%$ & & \\
\hline \multirow{2}{*}{ Floss } & Yes & 732 & \begin{tabular}{|l|}
$77.50 \%$ \\
\end{tabular} & \begin{tabular}{|l|}
285.038 \\
\end{tabular} & 0.001 \\
\hline & No & 213 & $22.50 \%$ & & \\
\hline \multirow{2}{*}{ Mouthwash } & Yes & 702 & $74.40 \%$ & 225.367 & 0.001 \\
\hline & No & 241 & $25.60 \%$ & & \\
\hline
\end{tabular}

\section{DISCUSSION}

People tend to neglect oral health, especially diseases that progress silently, such as periodontal diseases. However, periodontal disease poses an important public health problem that significantly impacts the oral and systemic health of individuals as well as their quality of life in general. Consequently, the public needs to develop a deeper understanding of the etiopathogenesis, risk factors associated with periodontal diseases, and various practices and attitudes that contribute to the prevention of the condition $[11,12]$.

For the dental healthcare educational programs to be efficient, it should be potentially directed toward populations that need health education the most. An efficient strategy to educate the public should target areas of least awareness. This study offered an inclusive overview of the general knowledge and awareness of the periodontal diseases' etiology, risk factors, and practice related behaviors among a representable sample of the adult Saudi population. The study was carried out at the two major universities and dental hospitals in Riyadh, KSA.

The results of the current study indicated that a high percentage of the surveyed participating adults recognized that periodontal disease could lead to tooth loss, can cause frequent pain, and can remain unrecognized for years and were aware of the signs of periodontal disease, including bleeding gums and gingival recession. However, there seems to be a problem with 
the awareness of the etiology of periodontitis, as indicated by the high percentage of respondents who did not know that periodontal disease is caused by plaque.

Croxon [13] investigated awareness of the public and patients' knowledge of periodontal health in a sample of the New Zealand population. The aim was to explore the subject of what awareness is and how people can become aware, as well as whether awareness is a necessary component in the treatment and management of periodontal diseases. The results of the two attitude and opinion surveys administered showed that there was great confusion in the minds of the patients over the relationship between the causes of periodontal disease and issues of care. He also reported that eleven years of New Zealand awareness programs have failed to significantly move the population's knowledge toward periodontal health and disease. In contrast to the findings of the current study, his data showed that the public was aware of the cause of periodontal disease and was less aware of the signs of the disease in their own mouth especially bleeding of gums.

While the data of the current survey suggest an extensive awareness of the general risk factors for the development of the periodontal disease, such as smoking and diabetes, an only small percentage of responders were able to recognize that periodontal diseases could possess risk factors for significant systemic conditions such as pre-term birth and coronary heart disease. These findings indicate severe discrepancies and knowledge gaps between risks associated with periodontitis and risk factors for periodontitis. This may be related to the fact that most of the public are unaware of the important and imperative link between oral and systemic diseases in general [14 - 16].

Oral health is a crucial component of systemic health. Periodontal diseases have been reported to be clearly related to some systemic diseases, such as coronary heart diseases, atherosclerosis, stroke, chronic kidney diseases, rheumatoid arthritis, diabetes, and pre-term labor [16 - 19]. This comorbidity often entails joint efforts by both dentists and physicians to identify the best treatment for each patient and may significantly affect the progression and prognosis of both diseases. The results of the current study indicated a low level of awareness of the link and association between periodontal disease and systemic health. These results are in line with those previously reported in literature [20 - 23].

The majority of subjects surveyed in this study reported an overall good understanding of the effective oral hygiene measures and practices that can help prevent periodontal disease and maintain good oral hygiene. Similar findings were reported in Germany, Jordan, Finland, and Norway [24 - 27].

\section{CONCLUSION}

The findings of the current study are part of the preliminary national data, including one region of Saudi Arabia and give a tentative representative for the level of periodontal disease awareness in the adult Saudi population. This may represent important information for the local dental health authorities and decision makers. While the data suggest a good overall understanding of the general concept of periodontal diseases, the risk factors associated with their development, as well as ways to prevent them and maintain good oral hygiene, there seemed to be a low level of awareness attributed towards the exact etiology of periodontal diseases and systemic complications linked to the disease. Limitations of the current study include the small sample size that may not represent the whole population of KSA, however, bigger samples and more comprehensive studies are being planned in the future.

In designing an effective public health educational program towards oral health, it would be recommended that more stress must be allocated to the subject of improving awareness of the strong correlation between periodontal health and systemic conditions and how preventing periodontal problems may reduce the risk of serious conditions, such as coronary heart diseases and premature labor.

\section{ETHICS APPROVAL AND CONSENT TO PARTICIPATE}

This study was approved by the Research Ethics Review Committee King Saud University, Riyadh, KSA, with approval no E-17-2736.

\section{HUMAN AND ANIMAL RIGHTS}

No animals were used in this research. All human research procedures followed were in accordance with the ethical standards of the committee responsible for human experimentation (institutional and national), and with the Helsinki Declaration of 1975, as revised in 2013.

\section{CONSENT FOR PUBLICATION}

All patients participated on a voluntary basis and gave their informed consent.

\section{AVAILABILITY OF DATA AND MATERIALS}

The data supporting the findings of the article is available in the Department of Periodontics and Community Dentistry, College of Dentistry, King Saud University, Riyadh, Saudi Arabia and will be available from corresponding author Dr. Nouf Alshibani (nalshibani@ksu.edu.sa) on request.

\section{FUNDING}

The authors would like to thank the College of Dentistry Research Centre and Deanship of Scientific Research at King Saud University, Saudi Arabia, for funding this research project.

\section{CONFLICT OF INTEREST}

The authors declare no conflict of interest, financial or otherwise.

\section{ACKNOWLEDGEMENTS}

Declared none.

\section{REFERENCES}

[1] Eke PI, Dye BA, Wei L, Thornton-Evans GO, Genco RJ. Prevalence of periodontitis in adults in the United States: 2009 and 2010. J Dent Res 2012; 91(10): 914-20.

[http://dx.doi.org/10.1177/0022034512457373] [PMID: 22935673]

[2] Raitapuro-Murray T, Molleson TI, Hughes FJ. The prevalence of 
periodontal disease in a Romano-British population c. 200-400 AD. Br Dent J 2014; 217(8): 459-66.

[http://dx.doi.org/10.1038/sj.bdj.2014.908] [PMID: 25342357]

[3] Locker D, Slade GD, Murray H. Epidemiology of periodontal disease among older adults: a review. Periodontol 2000 1998; 16: 16-33. [http://dx.doi.org/10.1111/j.1600-0757.1998.tb00113.x] [PMID: 10337302]

[4] Benjamin RM. Oral health: the silent epidemic. Public Health Rep 2010; 125(2): 158-9.

[http://dx.doi.org/10.1177/003335491012500202] [PMID: 20297740]

[5] Nazir MA. Prevalence of periodontal disease, its association with systemic diseases and prevention. Int J Health Sci (Qassim) 2017; 11(2): 72-80.

[PMID: 28539867]

[6] Guile EE. Periodontal status of adults in central Saudi Arabia. Community Dent Oral Epidemiol 1992; 20(3): 159-60.

[http://dx.doi.org/10.1111/j.1600-0528.1992.tb01554.x] [PMID: 1623711]

[7] Axelsson P, Lindhe J, Nyström B. On the prevention of caries and periodontal disease. Results of a 15 -year longitudinal study in adults. J Clin Periodontol 1991; 18(3): 182-9.

[http://dx.doi.org/10.1111/j.1600-051X.1991.tb01131.x] [PMID: 2061418]

[8] Watt RG, Petersen PE. Periodontal health through public health--the case for oral health promotion. Periodontol 2000 2012; 60(1): 147-55. [http://dx.doi.org/10.1111/j.1600-0757.2011.00426.x] [PMID: 22909112]

[9] Petersen PE, Ogawa H. The global burden of periodontal disease: towards integration with chronic disease prevention and control. Periodontol 2000 2012; 60(1): 15-39.

[http://dx.doi.org/10.1111/j.1600-0757.2011.00425.x] [PMID: 22909104]

[10] Flanders RA. Effectiveness of dental health educational programs in schools. J Am Dent Assoc 1987; 114(2): 239-42.

[http://dx.doi.org/10.14219/jada.archive.1987.0033] [PMID: 3469272]

[11] Tonetti MS, Jepsen S, Jin L, Otomo-Corgel J. Impact of the global burden of periodontal diseases on health, nutrition and wellbeing of mankind: A call for global action. J Clin Periodontol 2017; 44(5): 456-62.

[http://dx.doi.org/10.1111/jcpe.12732] [PMID: 28419559]

[12] Zhu L, Petersen PE, Wang HY, Bian JY, Zhang BX. Oral health knowledge, attitudes and behaviour of adults in China. Int Dent J 2005; 55(4): 231-41.

[http://dx.doi.org/10.1111/j.1875-595X.2005.tb00321.x] [PMID: 16167612]

[13] Croxson LJ. Practical periodontics. Awareness of periodontal disease-the patient. Int Dent J 1998; 48(3)(Suppl. 1): 256-60.

[http://dx.doi.org/10.1111/j.1875-595X.1998.tb00714.x] [PMID: 9779106]

[14] Formicola AJ. Dentistry and medicine, then and now. J Am Coll Dent 2002; 69(2): 30-4.

[PMID: 12132256]
[15] Cohen LA. Expanding the physician's role in addressing the oral health of adults. Am J Public Health 2013; 103(3): 408-12.

[http://dx.doi.org/10.2105/AJPH.2012.300990] [PMID: 23327256]

[16] Winning L, Linden GJ. Periodontitis and systemic disease: association or causality? Curr Oral Health Rep 2017; 4(1): 1-7.

[http://dx.doi.org/10.1007/s40496-017-0121-7] [PMID: 28303212]

[17] Manjunath BC, Praveen K, Chandrashekar BR, Rani RM, Bhalla A.

Periodontal infections: a risk factor for various systemic diseases. Natl Med J India 2011; 24(4): 214-9. [PMID: 22208140]

[18] Casanova L, Hughes FJ, Preshaw PM. Diabetes and periodontal disease: a two-way relationship. Br Dent J 2014; 217(8): 433-7. [http://dx.doi.org/10.1038/sj.bdj.2014.907] [PMID: 25342350]

[19] Ioannidou E, Swede H. Disparities in periodontitis prevalence among chronic kidney disease patients. J Dent Res 2011; 90(6): 730-4. [http://dx.doi.org/10.1177/0022034511402209] [PMID: 21422478]

[20] Gur A, Majra J. Awareness regarding the systemic effects of periodontal disease among medical interns in India. J Glob Infect Dis 2011; 3(2): 123-7.

[http://dx.doi.org/10.4103/0974-777X.81687] [PMID: 21731297]

[21] Al-Zarea BK. Oral health knowledge of periodontal disease among university students. Int J Dent 2013; 2013647397

[http://dx.doi.org/10.1155/2013/647397] [PMID: 23573091]

[22] Tarannum F, Prasad S, Vivekananda L, Jayanthi D, Faizuddin M. Awareness of the association between periodontal disease and preterm births among general dentists, general medical practitioners and gynecologists. Indian J Public Health 2013; 57(2): 92-5.

[http://dx.doi.org/10.4103/0019-557X.114992] [PMID: 23873196]

[23] Shangase SL, Mohangi GU, Hassam-Essa S, Wood NH. The association between periodontitis and systemic health: an overview. SADJ 2013; 68(1): 8-12, 10-12. [PMID: 23951755]

[24] Deinzer R, Micheelis W, Granrath N, Hoffmann T. More to learn about: periodontitis-related knowledge and its relationship with periodontal health behaviour. J Clin Periodontol 2009; 36(9): 756-64. [http://dx.doi.org/10.1111/j.1600-051X.2009.01452.x] [PMID: 19659893]

[25] Taani DQ. Periodontal awareness and knowledge, and pattern of dental attendance among adults in Jordan. Int Dent J 2002; 52(2): 94-8.

[http://dx.doi.org/10.1111/j.1875-595X.2002.tb00607.x] [PMID: 12013257]

[26] Karikoski A, Ilanne-Parikka P, Murtomaa H. Oral self-care and periodontal health indicators among adults with diabetes in Finland. Acta Odontol Scand 2001; 59(6): 390-5.

[http://dx.doi.org/10.1080/000163501317153257] [PMID: 11831490]

[27] Rise J, Sögaard AJ. Effect of a mass media periodontal campaign upon preventive knowledge and behavior in Norway. Community Dent Oral Epidemiol 1988; 16(1): 1-4. [http://dx.doi.org/10.1111/j.1600-0528.1988.tb00543.x] [PMID: 3422609]

This is an open access article distributed under the terms of the Creative Commons Attribution 4.0 International Public License (CC-BY 4.0), a copy of which is available at: https://creativecommons.org/licenses/by/4.0/legalcode. This license permits unrestricted use, distribution, and reproduction in any medium, provided the original author and source are credited. 